\title{
Mind and Folk Psychology: A Partial Introduction
}

\author{
Bruno Mölder \\ Department of Philosophy, University of Tartu
}

'Folk psychology' has become one of the central terms in contemporary philosophy of mind. In the 1980s, it had a wide currency in discussions about functionalism and eliminativism, and it has come to play a significant role in the study of mindreading or how we make sense of people's minds. Often, 'folk psychology' has been used to speak of our commonsense understanding of the mind and of mental states, an understanding that implicates the existence of a framework of concepts that we use to make sense of people's actions. Sometimes a stronger assumption is made; namely, that folk psychology is a kind of theory that fixes the meaning of mental terms, which then turn out to be theoretical terms. Moreover, some philosophers and psychologists assume that our implicit grasp of folk psychology is the very thing that makes social cognition possible. When we suppose that folk psychology plays some such fundamental role, what does that tell us about the concepts of mind and of mental states? Can we view mental states as folk psychological posits? Are there aspects of mind that extend beyond the purview of folk psychology?

The current issue is dedicated to topics related to folk psychology, mindreading and mental states. As folk psychology itself is a multifaceted phenomenon, the papers cover quite a broad area. The main portion of this introduction focuses on precisely the issue of the relationship between folk psychology and our notion of the mind. I clarify certain pertinent background assumptions and develop my own stance towards them. The setting that this introduction provides to the following papers is thus partial, in both senses of the term: it is not completely neutral nor does it aim to give a complete outline of the field. I hope to remedy this with an overview of each contribution in the last part of this introduction.

Corresponding author's address: Bruno Mölder, Department of Philosophy, Institute of Philosophy and Semiotics, University of Tartu, Ülikooli 18, 50090 Tartu, Estonia. Email: bruno.moelder@ut.ee. 


\section{The folk and the mental: Two assumptions}

Given the widespread use of the term 'folk psychology', it should not come as a surprise that it has been used in various different, albeit related, senses. It should also go without saying that those different senses come with varying commitments.

In the weakest sense, one can say that folk psychology is just the practice of attributing mental states to other people. Somewhat more substantially, 'folk psychology' can be taken to mean the ability to understand others' behavior in terms of mental states. Imputing the ability is more specific and demanding than simply pointing to an existing practice. To say that one has an ability is to make a claim about one's competence, which may be there even if it does not manifest itself in one's behavior. In addition, a single practice could be subserved by various different abilities. Third, 'folk psychology' might mean merely the commonsense conceptual framework that comprises the mentalistic terms used in the folk practice. Further, the framework might also be said to contain commonsense principles and generalizations, all either implicitly known or constructed from an external, philosophical vantage point. The first option corresponds to the theory-theory (an empirical hypothesis about our actual mindreading mechanism) and the other to the David Lewis's (1972) construal of functionalism. ${ }^{1}$ One could add even more padding to the notion and talk about folk psychology as a theory that has rich "Fodorian" commitments; such as representationalism, causation by content, Language of Thought etc. (as pointed out by Lycan 1997, 2-3).

Evidently some grouping of these different senses is needed if we are to keep our bearings in the midst of their diversity. It is important to distinguish the phenomenon from the explanation of the phenomenon. Both Daniel F. Hartner and Taavi Laanpere in their contributions to the present issue make a distinction of this sort. Laanpere distinguishes between the explanandum and explanans with regard to folk psychology. Hartner draws a line between the target phenomenon and the mechanism that is postulated to explain it. Proceeding from this distinction, the practice of mindreading, as well as the framework of concepts it employs, belong to the side of target phenomena, whereas the claims that mindreading is achieved by the application of some single ability, or by an implicit theory of mind or or by processes of mental simulation should be seen as explications of the mechanism that gives rise to the target phenomena.

Let me illustrate just how diverse the senses of 'folk psychology' are by walking through some of the ways in which philosophers working in the area

\footnotetext{
Stephen Stich and Ian Ravenscroft label the first one "internal" and the second as the "ex-
} ternal” reading of 'folk psychology' (see Stich 1996, 124-131). 
have defined the term. I begin with a retrospective quote by Daniel Dennett who claims authorship of the term, dating its conception to 1981 (see Dennett 1981). Although future historians of the philosophy of mind will, no doubt, sort this matter out, let me just note that in the same year the term also figured prominently in Paul Churchland's (1981) now classic eliminativist paper. ${ }^{2}$ Dennett conceives of folk psychology as an ability to interpret action in terms of beliefs and desires and he distinguishes this clearly from the claim that the ability involves a theory:

Probably the most important pattern in our manifest image, because it anchors so many other categories that matter to us, is the pattern I call folk psychology. I coined the term in its current meaning in 1981, but it apparently had an earlier incarnation in the writings of Wilhelm Wundt and Sigmund Freud and others (Volkpsychologie), where it meant something about national character (the Geist of the German Volk-you do not want to know). This was an antecedent I had missed, as did many others who adopted the term. I proposed folk psychology as a term for the talent we all have for interpreting the people around us-and the animals and the robots and even the lowly thermostats-as agents with information about the world they act in (beliefs) and the goals (desires) they strive to achieve, choosing the most reasonable course of action, given their beliefs and desires. ... Since everybody agrees that we have the interpretive talent, and everybody does not agree about how we manage to be so competent, I think it is best to keep 'theory' out of it and to use a somewhat more neutral term for the time being. ... Folk psychology is a talent we excel in without formal education. (Dennett 2013, 73-74)

The following is Paul Chuchland's resolute construal of folk psychology as a tacitly known and theoretical body of knowledge that contains laws for the explanation and prediction of behavior:

The fact is that the average person is able to explain, and even predict, the behavior of other persons with a facility and success that is remarkable. Such explanations and predictions standardly make reference to the desires, beliefs, fears, intentions, perceptions, and so forth, to which the agents are presumed subject. But explanations presuppose laws-rough and ready ones, at least-that connect the explanatory conditions with the behavior explained. The same is true for the making of predictions, and for the justification of subjunctive and counterfactual conditional concerning behavior. Reassuringly, a rich network of common-sense laws can indeed be reconstructed from

2 The term 'folk psychology' is also included to the index of Churchland's (1979) book, whereas in the text he talks about "the P-theory". He acknowledges his debt to Sellars (1956) for the idea that our commonsense conception of the mind is theoretical. 
this quotidean commerce of explanation and anticipation; its principles are familiar homilies; and their sundry functions are transparent. Each of us understands others, as well as we do, because we share a tacit command of an integrated body of lore concerning the lawlike relations holding among external circumstances, internal states, and overt behavior. Given its nature and functions, this body of lore may quite aptly be called 'folk psychology'. (Churchland 1981, 68-69)

Circa 15 years later he still understands folk psychology as a framework for predicting and explaining behavior. Note-and this will be important later on-how he presumes that the framework includes mental concepts:

'Folk psychology' denotes the prescientific, common-sense conceptual framework that all normally socialized humans deploy in order to comprehend, predict, explain, and manipulate the behaviour of humans and the higher animals. This framework includes concepts such as belief, desire, pain, pleasure, love, hate, joy, fear, suspicion, memory, recognition, anger, sympathy, intention, and so forth. (Churchland 1994, 308)

Stephen Stich also lists familiar mental terms and claims that folk psychology is a theory that regulates their use:

In our everyday dealings with one another we invoke a variety of commonsense psychological terms including 'believe', 'remember', 'feel', 'thinking,' 'desire,' 'prefer,' 'imagine', 'fear,' and many others. The use of these terms is governed by a loose knit network of largely tacit principles, platitudes, and paradigms which constitute a folk theory. Following recent practice, I will call this network folk psychology. (Stich $1983,1)$

Nichols and Stich (2003) make a stronger claim when they say that folk psychological information is actually put to use by internal mindreading mechanisms:

[T] he most natural interpretation, for both functionalists and eliminativists, is that folk psychology is a rich body of information about the mind that is utilized by the mental mechanisms responsible for mindreading. (Nichols and Stich 2003, 8, italics omitted)

More recently, Daniel Hutto defines folk psychology as a practice, but then moves swiftly to characterize it as an ability to use mental predicates:

Folk psychology (or FP) is a moniker devised by philosophers which is meant to designate a specific sub-section of our everyday talk of, and thought about, the mental... When used in an appropriately restricted sense, FP denotes-at a bare minimum-our everyday practice of making sense of intentional actions (i.e. our own and those of 
others) in terms of reasons, where this implies having a capacity for the competent invocation of propositional attitude talk. So construed, FP ... is a sophisticated, high level capacity; it involves being able to answer a particular sort of 'why'-question by skilfully deploying the idiom of mental predicates (beliefs, desires, hopes, fears, etc.). (Hutto 2009a, 10)

Given the variety of senses, it is important to be clear which notion one presumes when talking about 'folk psychology'; otherwise there is a danger of a mere verbal disagreement. ${ }^{3}$ So let me be clear in this regard: for the purposes of this introduction, I will understand 'folk psychology' primarily in the sense of a conceptual framework that includes certain familiar psychological terms as well as the links between them. ${ }^{4}$ Of course, this framework is put to practical use when we attribute mental states to others in order to make sense of their action, and this presumes a certain ability or set of abilities to apply the framework. The 'ability' and 'practice' senses of 'folk psychology' are thus related to the 'framework' sense, but they will not be in the foreground in what follows. This sort of usage is quite widespread, when people aim to include only relatively modest commitments in their interpretation of 'folk psychology' (e.g., Goldman 1993, 15; Von Eckhardt 1994, 300). The stronger and more controversial commitments (such as that the links in the framework constitute rules, principles or laws or empirical claims on the level of a mechanism that this framework is internally represented or has the form of a theory) need not be part of the 'framework' sense of 'folk psychology' This sense is also independent of the often presupposed view that the sole purpose of the framework is to explain and predict behavior. There are many other uses to which it can be put (Wilkes 1991, 25). Nor does the 'framework' sense commit us to the view that, when used descriptively, folk psychological descriptions should be read in a "realist" way.

An understanding of 'folk psychology' as a conceptual framework might be relatively modest compared to some other uses of this term, but such an

3 Two recent books on folk psychology agree with each other quite substantially when they each claim that attributing propositional attitudes is neither the only, nor the most central, way of making sense of others. However, they draw almost completely opposite conclusions. I think this is partly due to what they read into the notion. Kristin Andrews (2012, 7) takes 'folk psychology' to denote "nothing more than the commonsense understanding of other minds," and so she can be a pluralist about folk psychology while pointing out that the commonsense understanding is much richer than usually assumed. Matthew Ratcliffe proceeds from a rather loaded notion of folk psychology, understood as the attribution of propositional attitudes and he ends up advocating eliminativism about folk psychology because he takes it to be too narrow and a misleading philosophical construction of commonsense understanding (see Ratcliffe 2007, 224).

${ }^{4}$ I presume that terms express concepts and for the sake of simplicity ignore the differences between terms and concepts. 
understanding is far from innocent. It seems that in this way the locution 'usage of folk psychology' has come to mean 'speaking in terms of mental states' (or 'the mentalistic vocabulary' as it is sometimes called). I hope that the reader excuses some further quotations, so that I may demonstrate that there is indeed such a tendency:

$[F]$ olk psychology ... is the perspective that invokes the family of 'mentalistic' concepts, such as belief, desire, knowledge, fear, pain, expectation, intention, understanding, dreaming, imagination, self-consciousness, and so on. (Dennett 1987, 7)

By 'folk psychology' I mean the commonsense understanding and deployment of mentalistic concepts, especially the propositional attitudes. (Goldman 2000, 4)

Folk psychological explanations proceed by calling upon a common stock of familiar mental terms, which are deployed in systematic ways. In line with this, mentalistic vocabulary is generally regarded to be a kind of well-regimented and clearly demarcated domain that can be identified by its own specific set of rules. At its heart, we find intentional attitude psychology, which is - crucially - a kind of belief/desire psychology. (Hutto 2009b, 203)

Thus, to deploy folk psychology is to use mental terms. But which terms are mental? One (and perhaps an obvious) way to answer this question is to take seriously the idea that folk psychology constitutes a framework. Folk psychology is not just a random collection of mental terms-being a framework means that it also determines what belongs to this collection. In other words, folk psychology can be understood as something that settles which states are mental and which are not. Although this idea can be paired with the view that terms belonging to folk psychology are implicitly defined within it, just as theoretical terms are implicitly defined in a theory, the pairing is not obligatory. It is sufficient if there are conceptual connections between the elements in the framework, so that anything that is not interconnected in the relevant way is not part of the folk psychological framework. Of course, some links point also to environmental and behavioral conditions, so the framework is not isolated from the world. But these "external" conditions are not part of the framework itself. With these connections and links in the background, we can then understand and identify each member of the framework. In this sense we can say that mental states are individuated through the folk psychological framework. Let us call this 'The Folk Assumption':

The Folk Assumption: Mental states are individuated through folk psychology. 
In calling this 'an assumption' I aim to stress that this idea has the status of a tacit or implicit premise. It may not have been explicitly articulated by anyone in this way, but something like this seems to guide at least some philosophical discussions of folk psychology.

Another similarly tacit assumption can be constructed out of widespread talk about mental states when discussing matters of the mind. Often this may just be for the sake of simplicity, but taken literally, this becomes a substantial claim that can implicitly shape philosophical analysis. ${ }^{5}$ So let us make this one explicit too. According to this assumption, the mind is just a collection of mental states (e.g., beliefs, experiences, desires, thoughts, etc.). Brain states, bodily states and anything that cannot be construed as mental states are not part of the mind.

The Mentalist Assumption: the mind is solely composed of mental states.

When we combine these two assumptions, they yield a position that can be called 'The Folk-Mentalist Thesis':

The Folk-Mentalist Thesis (FMT): the mind is solely composed of mental states as individuated through folk psychology.

As we can see, this ties the notion of the mind very intimately to folk psychology. By making this position explicit, even if it is one that nobody has openly subscribed to, we can subject it to criticism and, if needed, then improve or reject it. Insofar it has been tacitly informing philosophical analyses, the upshot of such criticism is relevant for such analyses as well.

\section{The Folk-Mentalist Thesis and the scope of folk psychology}

Is the Folk-Mentalist Thesis tenable? In what follows, I bring out two possible and related concerns about FMT.

The first worry is related to an uneasy methodological consequence that can be drawn from FMT. If the mind is composed of nothing else but folk psychological states, then it is natural to think that the mind can be fully understood merely by investigating folk psychology. Or, more modestly, even if one builds up only a philosophical conception of the mind based on folk psychology, it would still remain isolated from other sciences (such as psychology or neuroscience) that also claim to be relevant to our understanding of the mind. Although it can be argued that the folk psychological conception of the mind serves different, non-explanatory aims or has some other

5 (Steward 1997) is one rare example of an effort to pay heed to the "statehood" of mental states and to distinguish them from mental events. 
features that ground its autonomy, it is hard to deny the relevance of scientific psychology and neuroscience. If so, there is the question of how scientific explanations relate to the folk psychological conception if the latter stands alone in isolation. (For more on the relationship between psychological and folk psychological explanations and on the autonomy of folk psychology, see (Bermúdez 2005) and Laanpere's paper in this issue.)

Second, even if we leave out these worries concerning isolation, there is still the question of whether folk psychology can capture the whole mind. If 'folk psychology' is another name for the set of mental terms, then the limits of folk psychology are also the limits of the mental. However, this seems too narrow. For there appear to be several phenomena that are related to the mind but which do not fit into the picture if FMT holds. The following is an open-ended list of such phenomena, which are at least prima facie troublesome for FMT:

(a) The processes happening at very short time-scales (up to hundreds of milliseconds) in which the usual conceptual distinctions of folk psychology do not apply. For example, Dennett (1991) has made an interesting case for the claim that at such time-scales one cannot distinguish between memory and experience and I think that this point can also be maintained independently of his multiple drafts model of consciousness. Presumably, we need then some new terms to describe the early stages of consciousness (see also (d)).

(b) The pre-linguistic states and processes that occur at an early stage in human development, especially in relation to other persons (e.g., mother-child reciprocity), labeled "primary intersubjectivity" by Trevarthen (1979).

(c) The intersubjective processes through which we understand other people that involve some kind of direct attunement to others (e.g., Gallagher 2008a). These are usually not described in terms of mental states, but rather with terms such as 'resonance' (Goldman 2008) or 'mirroring' (Gallese 2001).

(d) Certain psychological structures that underpin our conscious phenomenology (for example, the tripartite (retention-primal impression-protention) structure of time consciousness proposed by Husserl 1991) or other features of consciousness that cannot be characterized as mental states, strictly speaking (e.g., the unity of consciousness (Dainton 2006), or the affordance of certain situations). ${ }^{6}$

${ }^{6}$ For an example of affordance, the description of which is not given in terms of mental states causing action, see (Dreyfus and Kelly 2007, 52). 
These are some examples of mental phenomena that folk psychology does not seem to capture. ${ }^{7}$ If it does not (and I do not see how these phenomena are part and parcel of folk psychology as it is usually understood), then FMT would seem to be inadequate. ${ }^{8}$

At this point, the defender of folk psychology could object that the listed items are not really mental phenomena. And if they are not, then it is no objection that these are not part of our folk psychology. On the contrary, this is something to be expected if folk psychology circumscribes what is mental. Moreover, some of the above examples involve the terms that psychologists use to explain cognition, and that is not a purpose of the commonsense conception of the mind.

In response to this it should be remembered that experiences are mental. More precisely, there seems to be a sufficient experiential condition for being mental: a phenomenon is mental if having it is experiencing something. All of the listed phenomena are related to experience: they are either experiential processes or psychological structures that constitute experiences. Whether this conflicts with a folk-psychological criterion (one which takes a phenomenon to be mental when that phenomenon is individuated in folkpsychological terms), depends upon whether folk psychology includes experience. If it does, then the experiential condition is subsumed under a folk psychological criterion. Given this, the defender of folk psychology cannot say that these are not mental phenomena. Only when folk psychology is understood very narrowly as propositional attitude psychology would these criteria yield different results. But then it could be argued that there must be multiple sufficient criteria for the mental: it is sufficient for a phenomenon to be regarded as mental if either the folk psychological or the experiential criterion holds of it.

This explains why we can regard the listed phenomena as mental, but they would still be troublesome for FMT. From the folk psychological point of view, one can refer to them only vaguely as something experiential. More detailed specifications of them are couched in terms that go beyond commonsense. However, as noted, it would be wrong to conclude from this that descriptions in these terms are not about the mind. Explorations of these

7 Could the possibility of extended cognition (Clark and Chalmers 1998) be an additional stumbling-block for FMT? No. This possibility is orthogonal to the present discussion, as the Mentalist Assumption would hold even if cognitive states are realized by extracranial processes.

8 My objections to FMT here may remind one of a criticism of folk psychology by Churchland (1981), who-among other things-argued that folk psychology is inadequate as an explanatory theory, since it does not explain mental illnesses, learning, creativity, the function of sleep, memory, perceptual illusions and vision. However, I am not inclined to draw eliminativist conclusions from my objections. 
phenomena within phenomenology, psychology and neuroscience are relevant, for they can be viewed as targeting the processes that constitute experiences.

\section{Folk psychology extended}

Let us assume that the criticism of FMT outlined in the previous section holds. What to make of it? One option would be to dethrone folk psychology from its putative central position both in our conception of the mental and in the explanation of social cognition (for proposals in this direction see Ratcliffe 2007; Gauker 2003 and Morton 2003). Here, however, I would like to briefly explore a more conservative option that retains the central role of folk psychology, but extends its scope.

I begin with the observation that although it is a routine practice, there is no obligation to construe folk psychology narrowly as a framework of beliefs, desires, thoughts and memories. It can encompass much more. Folk psychology can be taken to incorporate pertinent contributions from scientific psychology and neuroscience, and it could also include those listed phenomena that did not fit into folk psychology narrowly construed. Let us dub the extended version of folk psychology 'folk psychology 2.o.' The traditional construal of folk psychology (as discussed above) would be then folk psychology 1.o. The candidates for a new vocabulary could include terms like 'resonance,' 'integration,' 'affordance': they can be considered part of folk psychology 2.0 if they become sufficiently integrated into the existing (and gradually extending) folk framework. ${ }^{9}$

Another example could be a philosopher's proposed addition to our existing taxonomy, critically discussed in Thompson's paper in this issue: the concept of alief suggested by Tamar Gendler (2008), an associative and habitual response disposition that is loaded with affect and leads to action. Of course, I do not mean to imply that any suggested new taxonomic item should be automatically incorporated into extended folk psychology. The merits of each case should be considered individually and the grounds for deciding whether a given proposal is useful still need working out. Research on particular kinds of such (putatively) mental phenomena is very useful in this regard. The studies of shared emotions by Bohl and pain by Kim et al. in the current issue are cases in point.

Although it is important to reflect on the conditions under which folk psychology could be extended, I am inclined to think that there are no clear-

9 The terms of folk psychology 2.o could thus also come from so-called 'subpersonal-level' accounts. There is a tendency to equate folk psychological talk with a personal-level story, though there can also be links to the subpersonal. (For the personal-subpersonal distinction, see Dennett 1969. 
cut facts of the matter about whether any new addition will really belong to extended folk psychology or not. Peter Godfrey-Smith nicely expresses a similar attitude in his statement on the status of 'belief' when moving, in the opposite direction, from folk psychology to scientific psychology:

Imagine ... a theory recognizing the core structural contrast between belief and desire, but embedding this contrast within a detailed picture that departs in many ways from folk psychology. ... Some cognitive scientists will want to retain folk-psychological terms like 'belief' for the states that are posited and described in this process; others may want to avoid these terms. To retain the term 'belief' is to stress the continuities between the scientific model and the folk psychological model, with respect to the basic interaction between 'how things are' and 'what I want' states. To drop the term is to stress the discontinuities between the scientific and the folk psychological picture. But there is no fact of the matter about whether the psychological states that appear in such a psychology 'really are beliefs'-whether they are the same states posited by folk psychology but more accurately described... There is no fact of the matter because folk psychology itself does not commit to a sufficiently definite specification of what beliefs are supposed to be like. (Godfrey-Smith 2004, 156-157)

Likewise, whether the extended framework still deserves the name 'folk psychology' depends upon whether there are enough continuities between the old and the extended framework, and whether these are important enough. I think that there are and that they are-but this is a pragmatic and not a factual matter.

Let me alleviate a possible worry. It has often been emphasized that folk psychology has a normative nature and that folk psychological stories are used to justify, evaluate and regulate behavior (Braaten 1988; McGeer 2007; Andrews 2015). According to this view, beliefs, desires and other folk psychology 1.0 states have various normative connections to each other. The new terms of folk psychology 2.0 are not part of this network, and when added, they would not be properly integrated (as far as normativity is concerned). In contrast to this, I think that the normativity of the folk psychological framework is not the crucial factor here. What matters is that the new terms will be connected to the old framework. Folk psychology 2.0 will come into effect when the new vocabulary is linked to other folk terms. If such links can be forged, they will acquire a normative import too.

One might wonder if this proposal predicts that the new vocabulary will be part of our everyday talk. To answer this question, we need to remember that folk psychology as a conceptual framework should not float free from folk psychological practice-the practice of understanding minds in folk psychological terms. Of course, the practice is not fixed and static and 
it develops over time. One should also distinguish between the folk psychology that people actually use and the philosophical portrayal of folk psychology. What has been expressed in the quotes I have listed here is inescapably the philosophical portrayal-the way the philosophers construe folk psychology. In other words, one could say that the philosophical portrayal gives an explicit description of people's implicit knowledge or conceptual ability that normally manifests itself in the practice. Folk psychology 2.0 is a kind of philosophical portrayal in this sense also. ${ }^{10}$ All I have suggested is that it might be a better description of the (evolving) practice than the traditional philosophical account of folk psychology (what I nicknamed 'folk psychology 1.0'). The proposal I am considering here is to update the philosophical construal of folk psychology. As such, it does not take a stand on the way people speak. Any possible change in ways of speaking depends upon just how widely the new vocabulary becomes explicitly known. ${ }^{11}$ It also depends on whether people would have a need to talk about those things in everyday life. However, what matters is what vocabulary they would use if such a need were to arise.

In sum, the proposal is to update the Folk Assumption in the following way:

The Revised Folk Assumption: Mental states are individuated through folk psychology 2.0.

By thus opening up folk psychology to inputs from science and philosophy, we can relieve the "isolation" worry. In order to cure the narrow-mindedness of FMT, the Mentalist Assumption needs revision too. Fortunately, there is an easy and obvious fix. Instead of only mental states, all mental phenomena (states, properties, events and processes) should be included.

The Revised Mentalist Assumption: The mind is solely composed of mental phenomena.

Giving up this version of the Mentalist Assumption would result in the strange view that the mind can be also composed of non-mental phenomena. So let us keep it. By conjoining these two revised assumptions, we get the revised FMT:

${ }^{10}$ Note that folk psychology 2.0 is not "regimented" folk psychology, i.e., folk psychology idealized for scientific purposes (like the intentional system theory of Dennett 1987). The latter would be folk psychology narrowed, not extended.

${ }^{11}$ The vocabulary of psychoanalysis could be seen as an example of specialist psychological vocabulary entering that of the masses (cf. Arminjon 2013). But in that case I would not claim that psychoanalytic vocabulary made an existing implicit understanding explicit. It rather shaped the path for a new conception of mental processes. 
The Revised Folk-Mentalist Thesis: The mind is solely composed of mental phenomena as individuated through folk psychology 2.0

This revised thesis allows us to incorporate the above-mentioned phenomena into the mind-phenomena which were troublesome for the original FMT. For they could be part of folk psychology 2.0, and they can still be regarded as phenomena if they are not states.

I will close this section with a remark on the relationship between mindreading and folk psychology, as I have discussed the latter here. Assuming that 'mindreading' means the understanding of others in terms of mental states, and assuming that folk psychology is a framework for mental states, does it follow that we only understand others in terms of folk psychology? The view that understanding others is only a matter of mindreading or "mentalizing" has recently been criticized by many authors (Gallagher 2001; Bermúdez 2003; Gauker 2003; Ratcliffe 2007; Andrews 2012). For example, Andrews $(2015,51)$ points out that besides mindreading, "we understand others in terms of individual properties such as personality traits and generalizations from past behavior, and in terms of group properties such as stereotypes and social norms."

I do not think that such a conclusion follows. We can distinguish mindreading from social cognition broadly speaking. Understanding others in terms of mental states is just one way of understanding other people and their actions. Very often we get by with others without thinking about their minds or attributing mental states to them. There is definitely no need to equate the application of folk psychology with social cognition. Even if we take 'folk psychology' in the extended sense, not all varieties of social cognition (such as those that rely upon stereotypes, inductive behavioral generalizations or shared social norms, etc.), should be included in this, as they also concern non-mental phenomena. These means of understanding others should count as examples of non-mentalistic social cognition. Thus, on the present proposal, we can say that mindreading is accomplished by using folk psychology 2.0, but this is not all there is to social cognition. ${ }^{12}$

\footnotetext{
${ }^{12}$ This proposal is thus more restrictive than Andrew's "pluralistic folk psychology" as she basically equals commonsense social cognition to folk psychology. Applying folk psychology 2.0 would be just one method amongst others (see Andrews 2015, 53-54). This difference can partly be explained by the fact that I am proceeding from the 'mentalistic framework' reading of folk psychology, whereas Andrews assumes that folk psychology is what is implicated in reading other people, not just their minds.
} 


\section{Overview of papers}

The above exploration of the link between folk psychology and the mind could not do justice to all of the topics addressed by the papers in this issue, as their range is quite wide, touching also upon such matters as selfknowledge, pre-linguistic understanding of others, normativity, infant and chimpanzee mindreading, pain and emotions. In what follows, I give a short overview of each paper, while also drawing attention to some connections between them.

Daniel Hartner presents a careful analysis of the term 'folk psychology', which he uses to refer both to people's mindreading activity and to their linguistic description of this activity. He warns against five conflations in the study of folk psychology: a) assuming that the concepts people use when reading minds are fully captured by the folk terms that figure in 'folk psychology' understood as a linguistic description; b) replacing the phenomenon that needs to be explained (mindreading) with a mechanism that provides just one possible explanation (the theory-theory); c) not distinguishing between a mechanism of mindreading (e.g., the theory-theory) and a philosophical theory about the nature of folk mental states (functionalism); d) not distinguishing between a theory of how mindreading actually works and a possible account of mind that could be constructed from folk psychology (e.g., the analysis of mental states as propositional attitudes). The root cause of these conflations, according to Hartner, is the "methodological problem" that our internal perspective (qua mindreaders) confounds our external perspective (qua the researchers of mindreaders). As researchers, we have no other linguistic framework for studying our actual mindreading activities than the lay language of folk psychology. He suggests that this methodological peculiarity gives psychology a kind of autonomy with respect to more fundamental sciences like neuroscience. But this is nothing to celebrate, as, for Hartner, this means that psychology is unable to study what the mind is really like. It rather describes the mind in terms of our folk psychological framework.

Taavi Laanpere also starts out by distinguishing between different senses of 'folk psychology.' Proceeding from the notion of folk psychology as a set of mental concepts, he focuses on the autonomy of explanations couched in folk psychological vocabulary. Such autonomy is often based on the idea that the ascription of mental states relies upon normative principles of rationality and thus are normative themselves as a result-they incorporate commitments about how one ought to act. This is supposed to make such explanations immune to revisions from causal explanations couched in subpersonal terms. Laanpere argues against this move by pointing out that several propositional attitude concepts are in fact normatively indistinguishable. If they 
do not make a unique normative contribution to a subject's "rational profile," then their distinctness lies elsewhere, in their descriptive content. But there are no obstacles impeding the entrance of such contents into causal explanations or their appearance within subpersonal-level statements. $\mathrm{He}$ concludes that the autonomy of folk psychology cannot be founded upon normative considerations.

J. Robert Thompson addresses the issue of adding new informational mental states to the psychological taxonomy. By the latter, he does not mean a folk-psychological taxonomy, but a (philosophically) regimented taxonomy of psychological states that stems from the familiar folk notions. The apparent need to expand the psychological taxonomy is suggested by certain puzzling phenomena such as delusions, addiction, blindsight and cases in which one's self-avowed beliefs conflict with one's actions. In Thompson's view, the psychological taxonomy need not be expanded by postulating new informational states, for the puzzling phenomena can be explained in terms of subdoxastic states and beliefs; especially when we recognize that there are various doxastic or belief-like states. In particular, Thompson focuses upon the question of whether we need to add "aliefs" to the psychological taxonomy. Aliefs are evidence-insensitive, habitual states posited by Gendler (2008) in which the information carried by the state is inseparable from its action-guiding aspects. Thompson argues that aliefs are not well-defined and do not yield any explanatory advantage. Thus their introduction is not justified.

What does it take to share mental states? Vivian Bohl focuses on emotions, especially on infants' positive emotions, for which Joel Krueger (2013) has defended the "Joint Ownership Thesis" (JOT) - the idea that the same episode of emotion is owned by more than one individual at the same time. She provides a thorough criticism of JOT and outlines her own approach to shared emotions. Bohl takes a shared emotion to be a kind of socialrelational emotion. Shared emotions arise within existing social relationships and can be analyzed in terms of the relational models theory and the dynamical systems approach. Shared emotions are understood by the participants of the interactive episode in the light of their ongoing relationship. Phenomenologically speaking, they have the quality of a sense of onenessthe emotion is seen as fostering the mutual relationship. Shared emotions cannot be maintained alone and they may arise in a synchronous manner between people, but they would still remain individual states, in contrast to Krueger's idea of joint ownership.

Philosophers often operate with their preferred construal of folk psychology. But is this in accord with the way the folk understand their states? This is an empirical question, which in recent years has been put forward by ex- 
perimental philosophers who seek to find out what the folk actually think. It turns out that often the "actual folk" differ from "philosophers' folk". Hyoeun Kim, Nina Poth, Kevin Reuter and Justin Sytsma present their empirical studies of the ordinary concept of pain. Their aim was to see if the philosophers' common understanding of the folk concept of pain as a private and subjective mental state can be empirically supported and whether there are cultural differences in the folk understanding of pain. Their studies with American and South Korean respondents show that in contrast to the common philosophical conception, the folk conception takes pain to be a bodily state. There seem to be several bodily conceptions: one locates the pain where the body is damaged, the other locates it in the location where pain is felt to be (a location which can be different from the damaged part of the body). No cultural differences were found with respect to the issue of whether pains are conceived of as mental or as bodily states. Both groups predominantly view pains as states of the body and are divided between the two versions of the bodily conception. However, South Koreans tend to prefer the first version of the bodily conception-the one that locates the pain in where the body is damaged.

The following papers deal with folk psychology understood as mindreading and its kin. Leon de Bruin proceeds from the "mindshaping" account of folk psychology (McGeer 2007; Hutto 2008; Zawidzki 2013). According to the mindshaping approach, in contrast to descriptive accounts of mindreading, folk psychology is a normative framework in the service of shaping people's minds and behavior in order to make them intelligible. It is because we share this framework, and because we participate in a common practice of shaping our minds in accordance with this framework, that the otherwise very complex task of interpreting other people becomes feasible (McGeer 2007). Whereas the mindshaping idea is usually applied to persons other than oneself, de Bruin inquires into whether this idea could also work for self-knowledge. Based on McGeer's views on "self-regulative agency," de Bruin applies the mindshaping approach to the first person and conceives of folk psychology as a practice of bringing one's mental states, habits, avowals and actions into line with each other, in a way that fits our social norms.

Another alternative to standard mindreading accounts is Interaction Theory (Gallagher 2001; 2008b), which states that mentalizing or the attribution of beliefs and desires is quite rare in everyday social interaction. Instead, we make sense of others by responding interactively to them and by seeing directly in an embodied way what they are up to. Uku Tooming's paper deals with the status of mentalizing in the interactionist account. He reasons as follows. Since interactionists do not deny that we sometimes attribute propositional attitudes, they need to explain why we do it if this is not 
needed for day-to-day social interaction. They usually rely on what Tooming calls the "Justificatory Role Account": we begin to infer and attribute beliefs and desires when the other's behavior is irrational or violates tacitly assumed norms. Tooming points out that this explanation does not hold up since there are simpler justifications for such cases that do not involve the attribution of beliefs and desires. He then proposes an account of belief and desire attribution that interactionists could resort to. This is based on Christopher Gauker's (2003) communicative conception. Tooming extends this conception to communication through gesture. At the most basic level, making belief and desire attributions then comes down to declarative and imperative pointing on other people's behalf.

Accounting for mindreading in infants and chimpanzees involves special difficulties. Because their performance in mindreading tasks is below the level of advanced mindreaders, it is not obvious that it can be explained in a mentalistic way. A mentalistic account (according to which infants and chimpanzees understand and attribute mental states to others) has been contested by more minimalist non-mentalistic approaches (according to which they either read only behavior or attribute states which differ from full-blown mental states). The last two papers in this issue deal with these themes. They both present an approach to basic socio-cognitive abilities that is more minimalist than the standard mentalistic account.

Laura Danón builds upon the suggestion by Lurz and Krachun (2011) that chimpanzees attribute "pushmi-pullyu representations" to others. This term comes from Millikan (1996), who uses it to designate certain primitive representations in which informational and directive functions are intertwined. (In this respect they are similar to the aliefs that are discussed in Thompson's paper.) Millikan has also distinguished pure pushmi-pullyu representations from their more complex variants in which the directive part is exercised only when further motivational states are present or where the situation affords more than one alternative course of action. In her paper, Danón presents a taxonomy of three types of basic mindreading, each corresponding to an ability to attribute a different kind of pushmi-pullyu representation and discusses chimpanzee and infant mindreading in light of these distinctions.

Marco Fenici and Tadeusz W. Zawidzki discuss infant social cognition, focusing upon infants' understanding of action as exhibited in spontaneous false belief tasks. They defend an alternative, non-mentalistic account on which infants track short-lived bouts of behavior and relate them to external goals and the most efficient means to those goals. They reject the mentalistic account that takes infants to attribute mental states to the enduring minds of other agents. 
In conclusion, let me express the hope that this volume incites further discussions on the many facets of the mind and folk psychology.

\section{Acknowledgements}

The research for this paper and the editing of this issue was supported by the Estonian Science Foundation grant ETF9117 ('Mind without mental states?'), the Centre of Excellence in Estonian Studies (European Union, European Regional Development Fund) and is related to research project IUT20-5 (Estonian Ministry of Education and Research). The printing of this issue has been supported by grant ETF9117 and by the University of Tartu publishing subsidy scheme. Versions of this paper have been presented to audiences in Konstanz, Tallinn and Krakow and I am grateful to the participants in these occasions for their comments and questions and to Alexander Davies for checking my English.

\section{Bibliography}

Andrews, K. (2012). Do Apes Read Minds? Toward a New Folk Psychology, The MIT Press, Cambridge, MA.

Andrews, K. (2015). The folk psychological spiral: Explanation, regulation, and language, The Southern Journal of Philosophy 53: 50-67.

Arminjon, M. (2013). Is psychoanalysis a folk psychology?, Frontiers in Psychology 4: 1-9.

Bermúdez, J. L. (2003). The domain of folk psychology, in A. O'Hear (ed.), Minds and Persons, Royal Institute of Philosophy Supplements (Book 53), Cambridge University Press, pp. 25-48.

Bermúdez, J. L. (2005). Philosophy of Psychology, Routledge, London.

Braaten, J. (1988). Elimination, enlightenment and the normative content of folk psychology, Journal for the Theory of Social Behaviour 18: 251-268.

Churchland, P. M. (1979). Scientific Realism and the Plasticity of Mind, Cambridge University Press, Cambridge.

Churchland, P. M. (1981). Eliminative materialism and the propositional attitudes, Journal of Philosophy 78: 67-90.

Churchland, P. M. (1994). Folk psychology (2), in S. Guttenplan (ed.), A Companion to the Philosophy of Mind, Blackwell, Oxford, pp. 308-316.

Clark, A. and Chalmers, D. (1998). The extended mind, Analysis 58: 7-19. 
Dainton, B. (2006). Stream of Consciousness: Unity and Continuity in Conscious Experience, and edn, Routledge, London.

Dennett, D. C. (1969). Content and Consciousness, Routledge, London.

Dennett, D. C. (1981). Three kinds of intentional psychology, in R. Healey (ed.), Reduction, Time and Reality, Cambridge University Press, Cambridge, pp. 37-61.

Dennett, D. C. (1987). The Intentional Stance, The MIT Press, Cambridge, MA.

Dennett, D. C. (1991). Consciousness Explained, Little, Brown \& Co, Boston.

Dennett, D. C. (2013). Intuition Pumps and Other Tools for Thinking, W. W. Norton \& Co, New York.

Dreyfus, H. and Kelly, S. (2007). Heterophenomenology: Heavy-handed sleight-of-hand, Phenomenology and the Cognitive Sciences 6: 45-55.

Gallagher, S. (2001). The practice of mind: Theory, simulation, or interaction?, Journal of Consciousness Studies 8: 83-107.

Gallagher, S. (2008a). Direct perception in the intersubjective context, Consciousness and Cognition 17: 535-543.

Gallagher, S. (2008b). Inference or interaction? Social cognition without precursors, Philosophical Explorations 11: 163-174.

Gallese, V. (2001). The 'Shared Manifold' hypothesis: From mirror neurons to empathy, Journal of Consciousness Studies 8: 33-50.

Gauker, C. (2003). Words without Meaning, The MIT Press, Cambridge, MA.

Gendler, T. (2008). Alief in action (and reaction), Mind \& Language 23: 552585.

Godfrey-Smith, P. (2004). On folk psychology and mental representation, in H. Clapin, P. Staines and P. Slezak (eds), Representation in Mind: New Approaches to Mental Representation, Elsevier, Oxford, pp. 147-162.

Goldman, A. (1993). The psychology of folk psychology, Behavioral and Brain Sciences 16: 15-28.

Goldman, A. (2000). Folk psychology and mental concepts, Protosociology 14: 4-25.

Goldman, A. (2008). Simulating Minds: The Philosophy, Psychology, and Neuroscience of Mindreading, Oxford University Press, Oxford.

Husserl, E. (1991). On the Phenomenology of the Consciousness of Internal Time, Kluwer, Dordrecht. Edited and translated by J. B. Brough. 
Hutto, D. (2008). Folk Psychological Narratives: The Sociocultural Basis of Understanding Reasons, The MIT Press, Cambridge, MA.

Hutto, D. D. (2009a). Folk psychology as narrative practice, in D. D. Hutto (ed.), Narrative and Folk Psychology, Imprint Academic, Exeter, pp. 9-39.

Hutto, D. D. (2009b). Lessons from Wittgenstein: Elucidating folk psychology, New Ideas in Psychology 27: 197-212.

Krueger, J. (2013). Merleau-Ponty on shared emotions and the joint ownership thesis, Continental Philosophy Review 46: 509-531.

Lewis, D. K. (1972). Psychophysical and theoretical identifications, Australasian Journal of Philosophy 50: 249-258.

Lurz, R. and Krachun, C. (2011). How could we know whether nonhuman primates understand other's internal goals and intentions? Solving Povinelli's problem, Review of Philosophy and Psychology 2: 449-481.

Lycan, W. (1997). Folk psychology and its liabilities, in M. Carrier and P. K. Machamer (eds), Mindscapes: Philosophy, Science, and the Mind, University of Pittsburgh Press, Pittsburgh, pp. 1-21.

McGeer, V. (2007). The regulative dimension of folk psychology, in D. D. Hutto and M. Ratcliffe (eds), Folk Psychology Re-Assessed, Springer, Dordrecht, pp. 137-156.

Millikan, R. (1996). Pushmi-pullyu representations, in J. Tomberlin (ed.), Philosophical Perspectives, Vol. 9, Ridgeview Publishing, Atascadero, CA, pp. 185-200.

Morton, A. (2003). The Importance of Being Understood: Folk Psychology as Ethics, Routledge, London.

Nichols, S. and Stich, S. P. (2003). Mindreading: An Integrated Account of Pretence, Self-Awareness, and Understanding Other Minds, Clarendon Press, Oxford.

Ratcliffe, M. (2007). Rethinking Commonsense Psychology: A Critique of Folk Psychology, Theory of Mind and Simulation, Palgrave Macmillan, Basingstoke.

Sellars, W. (1956). Empiricism and the philosophy of mind, in H. Feigl and M. Scriven (eds), Minnesota Studies in the Philosophy of Science, Volume I: The Foundations of Science and the Concepts of Psychology and Psychoanalysis, University of Minnesota Press, Minnesota, pp. 253-329.

Steward, H. (1997). The Ontology of Mind: Events, Processes and States, Clarendon Press, Oxford. 
Stich, S. P. (1983). From Folk Psychology to Cognitive Science: The Case Against Belief, The MIT Press, Cambridge, MA.

Stich, S. P. (1996). Deconstructing the Mind, Oxford University Press, Oxford.

Trevarthen, C. (1979). Communication and cooperation in early infancy. A description of primary intersubjectivity, in M. Bullowa (ed.), Before Speech: The Beginning of Human Communication, Cambridge University Press, Cambridge, pp. 321-347.

Von Eckhardt, B. (1994). Folk psychology (1), in S. Guttenplan (ed.), A Companion to the Philosophy of Mind, Blackwell, Oxford, pp. 300-307.

Wilkes, K. (1991). The relationship between scientific psychology and common-sense psychology, Synthese 89: 15-39.

Zawidzki, T. W. (2013). Mindshaping: A New Framework for Understanding Human Social Cognition, The MIT Press, Cambridge, MA. 